\title{
Correction to: Updated Recommendations on Cardiovascular Prevention in 2022: An Executive Document of the Italian Society of Cardiovascular Prevention
}

\author{
Massimo Volpe ${ }^{1}\left(\right.$ Giovanna Gallo $^{1} \cdot$ Maria Grazia Modena ${ }^{2} \cdot$ Claudio Ferri $^{3} \cdot$ Giovambattista Desideri $^{3}$. \\ Giuliano Tocci ${ }^{1}$. Members of the Board of the Italian Society of Cardiovascular Prevention
}

Published online: 7 March 2022

(c) The Author(s) 2022

\section{Correction to: \\ High Blood Pressure \& Cardiovascular Prevention https://doi.org/10.1007/s40292-021-00503-4}

In the online version of the article section 8 (Obesity), para 6 , lines 1 to 5 which read as:

Medications approved in Europe for weight loss in obese subjects currently include the lipase inhibitor orlistat at the dosage of $120 \mathrm{mg}$, of the GLP1-RA semaglutide $3 \mathrm{mg}$ administered weekly and the combination of naltrexone and bupropione.

should read:

Medications approved in Europe for weight loss in obese subjects currently include the lipase inhibitor orlistat at the dosage of $120 \mathrm{mg}$, the GLP1-RA liraglutide $3 \mathrm{mg}$ administered daily or semaglutide $2.4 \mathrm{mg}$ administered weekly and the combination of naltrexone and bupropione.

In online version of the article Section 8 (Obesity), table (New recommendation), third point which reads as:

The original article can be found online at https://doi.org/10.1007/ s40292-021-00503-4

Massimo Volpe

massimo.volpe@uniroma1.it

1 Cardiology Unit, Division of Cardiology, Department of Clinical and Molecular Medicine, Faculty of Medicine and Psychology, University of Rome Sapienza, Sant'Andrea Hospital, Rome, Italy

2 Department of Cardiology, Università degli Studi di Modena e Reggio Emilia, Policlinico di Modena, Modena, Italy

3 Department of Life, Health, and Environmental Sciences, University of L'Aquila, S. Salvatore Hospital, L'Aquila, Italy
Medications for weight loss in obese subjects, including orlistat, semaglutide and the combination of naltrexone and bupropione may be considered when energy restriction and exercise are not sufficient.

should read:

Medications for weight loss in obese subjects, including orlistat, liraglutide, semaglutide and the combination of naltrexone and bupropione may be considered when energy restriction and exercise are not sufficient.

The original article has been corrected.

Open Access This article is licensed under a Creative Commons Attribution-NonCommercial 4.0 International License, which permits any non-commercial use, sharing, adaptation, distribution and reproduction in any medium or format, as long as you give appropriate credit to the original author(s) and the source, provide a link to the Creative Commons licence, and indicate if changes were made. The images or other third party material in this article are included in the article's Creative Commons licence, unless indicated otherwise in a credit line to the material. If material is not included in the article's Creative Commons licence and your intended use is not permitted by statutory regulation or exceeds the permitted use, you will need to obtain permission directly from the copyright holder. To view a copy of this licence, visit http://creativecommons.org/licenses/by-nc/4.0/. 